\title{
Post Hepatectomy Liver Failure in Nutshell
}

\author{
Sugi RV Subramaniam, Senthil Kumar Perumal, Kamalakannan Rajendran, Sugumar Chidambaranathan, \\ Jeswanth Sathyanesan and Ravichandran Palaniappan
}

Institute of Surgical Gastroenterology \& Liver Transplant, Govt. Stanley Medical College, India

Submission: September 10, 2018; Published: October 05, 2018

"Corresponding author: Sugi RV Subramaniam, Surgical Gastroenterology Resident, Institute of Surgical Gastroenterology \& Liver Transplant, Govt Stanley Medical College \& Hospital, 601, Old Jail Road, Chennai, Royapuram, Tamil Nadu, India, Pin Code: 600001, Tel: +917299058581;

Email: drrvsugi@gmail.com

\section{Abstract}

Hepatic resections are the most complex operative interventions that we do today with a mortality rate as high as $30 \%$. Post-Hepatectomy Liver Failure (PHLF) is a major source of morbidity and mortality after hepatectomies with an incidence of up to $10 \%$ of cases. Lower rate of PHLF are reported in East Asian countries (1-2\%), but when present, PHLF leads to significant morbidity and mortality.

Keywords: Post hepatectomy liver failure; 50-50 criterion; Hepatic resection

\section{Introduction}

Defining what is PHLF and criteria to diagnose it were equally difficult as treating a PHLF. The International Study Group of Liver Surgery: considering the normal postoperative course of serum bilirubin concentration and International Normalized Ratio defined PHLF as the impaired ability of the liver to maintain its synthetic, excretory, and detoxifying functions, which are characterized by an increased INR and concomitant hyperbilirubinemia on or after postoperative day 5 [1].

\section{Criteria to define and diagnose PHLF includes}

\section{a) Model for end stage liver disease (MELD) score}

MELD is a widely used criteria which incorporates serum creatinine, INR, and bilirubin in a complex mathematical formula computation given by

MELD Score $=10^{*}((0.957 * \ln ($ Creatinine $))+(0.378 * \ln$ $($ Bilirubin $))+(1.12 * \ln (\mathrm{INR})))+6.43$

\section{b) $50-50$ criterion}

This does not account for any clinical parameters and relies only on two laboratory values namely Prothrombin Time [PT] and serum bilirubin on post-operative day 5 . The association of PT $<50 \%$ and SB $>50 \mu \mathrm{ml} / \mathrm{L}$ on POD 5 was a simple, early, and accurate predictor of more than $50 \%$ mortality rate after hepatectomy. These criteria could be identified early enough, before clinical evidence of complications, for specific interventions to be applied in due time [2].

\section{Preoperative risk assessment}

CT-based volumetric analysis: A helical CT scan to assess the volume of resection by semi-automated contouring of the liver. Shoup et al observed that the percentage of remaining liver was closely correlated with increasing prothrombin time $(>18$ seconds) and bilirubin level ( $>3 \mathrm{mg} / \mathrm{dL}$ ). PHLF was noted more often in patients undergoing trisegmentectomy especially those with $\leq 25 \%$ of liver remaining.

Indocyanine green (ICG) clearance and ICG retention rate (ICG R15): All ICG administered is cleared by normal liver. ICG reflects intra-hepatic blood flow which can be used to assess liver functional reserve in patients with cirrhosis. Application of ICG and ICG R15 to estimating functional hepatic reserve after resection of normal livers in the setting of malignancy is an effective method. ICG elimination is measured by pulse spectrophotometry \& indocyanine green plasma disappearance rate (ICG PDR) is determined. The foremost advantage of ICG is that it is a noninvasive tool for prediction of PHLF [3]. When the pre-operative ICG PDR was less than $17.6 \% / \mathrm{min}$ and the preoperative serum bilirubin was $>17 \mu \mathrm{mol} / \mathrm{L}$, the positive predictive value for post-operative liver dysfunction was $75 \%$, and the negative predictive value was $90 \%$.

Galactosyl human serum albumin (GSA) scintigraphy: 99mTc diethylenetriamine-pentaacetic acid-Galactosyl human Serum Albumin (GSA) scintigraphy for the pre-operative evaluation of cirrhotic patients is a valid method for pre-operative 
risk assessment. The molecule is taken up by the liver, reflecting the volume of functional liver. Uptake corresponds to bilirubin level, INR, and ICG clearance. GSA is unaffected by hyperbilirubinemia and offers a highly accurate estimation of FLR. In nearly $20 \%$ of patients, the severity of liver disease is underestimated by ICG clearance testing, and better represented by GSA scintigraphy.

99mTc-mebrofenin: 99mTc-mebrofenin is excreted into the bile by adenosine triphosphate-dependent export pumps namely the multidrug-resistance-associated proteins 1 and 2, without undergoing biotransformation during transit through the hepatocytes. This preoperative total hepatic uptake rate of $99 \mathrm{mTc}-$ mebrofenin correlates well with the indocyanine green

Table 1: Methods and techniques to minimize PHLF
(ICG) clearance rate. In patients with parenchymal disease and hilar cholangiocarcinoma 99mTc-mebrofenin uptake in the future remnant liver on functional hepatobiliary scintigraphy has been proved to be more valuable than measurement of the volume of the future remnant in the assessment of the posthepatectomy risk of liver failure and liver failure-related mortality.

*To avoid irreversible injury to the liver, the Pringle maneuver should be applied in an intermittent manner, and the duration should not exceed a total of 120 minutes. *Pringle maneuver during liver transection is safe and effective and can be employed, in an intermittent manner, during hepatectomy of whatever histology of nontumorous liver [4] (Table 1).

\begin{tabular}{|c|}
\hline Preoperative \\
\hline Nutritional supplementation \\
\hline Aggressive management of co-morbid conditions \\
\hline Portal vein embolization [PVE] to enlarge FLR \\
\hline Intra Operative \\
\hline Avoidance of skeletonization of hepatoduodenal ligament unless required for R0 resection \\
\hline Minimize EBL (resection under low CVP conditions) ${ }^{*}$ \\
\hline Avoidance of blood transfusions if able \\
\hline Close attention to hemostasis to avoid post-operative hemorrhage \\
\hline Parly recognition and treatment of post-op hemorrhage \\
\hline Early recognition and treatment of biliary obstruction or leak \\
\hline Early recognition and treatment of intra-abdominal infection \\
\hline
\end{tabular}

\section{Estimation of Remaining Functional Parenchyma}

Bismuth et al proposed a formula to estimate amount of functional parenchyma remaining after resection (Mr), Where Me is the quantity of functional liver removed and Mt the total quantity of functional liver. PBC the Paul Brousse Hospital classification.

\section{$\mathrm{Mr}=\mathrm{Me} / \mathrm{Mt} \mathrm{X} \mathrm{PBC}$}

Postoperative mortality or complications are not dependent on the amount of resected parenchyma alone. There was a $5 \%$ mortality even after minimal resection. Postoperative liver failure is precipitated in over $50 \%$ of patients by sepsis, hemorrhage or portal thrombosis. Incidence of late liver failure is rare $[<5 \%]$ with almost nil mortality when estimated postoperative liver volume $>35 \%$. Normal livers regenerate completely within 3 months, while in cirrhosis or chronic hepatitis it may take up to 9-12 months or even longer to reach preoperative liver volume. The speed of hepatic regeneration appears to be a function of the volume resected.

\section{Treatment of PHLF (Table 2)}

\section{Treatment of PHLF remains difficult}

Table 2: Consensus definition and severity grading of posthepatectomy liver failure by the ISGLS

\begin{tabular}{|c|c|}
\hline Grade A & Abnormal laboratory parameters; requiring no change in the clinical management \\
\hline Grade B & Deviation from the regular clinical management but manageable without invasive treatment \\
\hline Grade C & Deviation from the regular clinical management and requiring invasive treatment \\
\hline
\end{tabular}


i. Pulmonary, renal and circulatory disturbances should be treated with a goal-directed therapy regime.

ii. Diuretics and renal replacement therapy have to be used as indicated

iii. In pulmonary insufficiency, noninvasive or invasive ventilation has to be used.

\section{Specific treatment of hepatic insufficiency}

Goal-directed therapy: Human albumin, fresh frozen plasma or AT III to cover the liver function

Liver support systems have been available for some years now: Molecular absorbent recirculating system (MARS), Modified fractionated plasma separation and adsorption (Prometheus)and Bioartificial liver and extracorporeal liver assist device

Liver transplantation: Salvage transplantation as the last resort

\section{Conclusion}

PHLF is a severe deadly complication. Mild hepatic insufficiency with a transient hyperbilirubinemia that does not alter the expected post-operative course is quite common. Multi-system failure requiring invasive treatment in ICU and multiple factors increase the risk of mortality. Obesity, diabetes, neoadjuvant treatment with chemotherapy, underlying cirrhosis, increased age, male gender, need for extended liver resection, and long operation with high intra-operative Estimated Blood Loss. Risk of PHLF can be minimized by accurate preoperative assessment of FLR, induction of hypertrophy of the liver remnant via PVE if the expected FLR is $<20 \%$ for a normal liver, $<30 \%$ for a steatotic liver and $<40 \%$ for a cirrhotic liver. PHLF is rather easy to prevent than to treat [5].

\section{References}

1. Rahbari NN, Garden OJ, Padbury R, Brooke-Smith M, Crawford M, et al. (2011) Posthepatectomy liver failure: a definition and grading by the International Study Group of Liver Surgery (ISGLS). Surgery 149(5): 713-724.

2. Balzan S, Belghiti J, Farges O, Ogata S, Sauvanet A, et al. (2005) The "50-50 criteria" on postoperative day 5: an accurate predictor of liver failure and death after hepatectomy. Ann Surg 242(6): 824-828.

3. de Liguori Carino N, O’Reilly DA, Dajani K, Ghaneh P, Poston GJ, et al. (2009) Perioperative use of the Li MON method of indocyanine green elimination measurement for the prediction and early detection of post-hepatectomy liver failure. Eur J Surg Oncol 35(9): 957-962.

4. Man K, Fan ST, Ng IO, Lo CM, Liu CL, et al. (1997) Prospective Evaluation of Pringle Maneuver in Hepatectomy for Liver Tumors by a Randomized Study. Ann Sur 226(6): 704-713.

5. Asencio JM, García Sabrido JL, Olmedilla L (2014) How to expand the safe limits in hepatic resections? J Hepatobiliary Pancreat Sci 21(6): 399-404.
Your next submission with JuniperPublishers will reach you the below assets

- Quality Editorial service

- Swift Peer Review

- Reprints availability

- E-prints Service

- Manuscript Podcast for convenient understanding

- Global attainment for your research

- Manuscript accessibility in different formats

( Pdf, E-pub, Full Text, audio)

- Unceasing customer service

Track the below URL for one-step submission https://juniperpublishers.com/online-submission.php 